\title{
Hazards of Environmental Disruption in Mine Goafs and Stability Evaluation in Gaofeng Mining Area
}

\author{
Chun Bai*, Meng Xian Yun** and Jun Mei Wang*† \\ *College of Civil Engineering, Xuchang University, Xuchang, 461000, China \\ **Zhumadian Cigarette Factory of China Tobacco Henna Industrial. CO, LTD \\ †Corresponding author: Jun Mei Wang; ansysbc@163.com
}

\section{Nat. Env. \& Poll. Tech. Website: www.neptjournal.com \\ Received: 28-04-2020 \\ Revised: $18-06-2020$ \\ Accepted: 15-07-2020 \\ Key Words: \\ Mine goafs \\ Environmental damage \\ Stability evaluation \\ Gaofeng mining area}

\begin{abstract}
China is rich in mineral resources with many points and broad faces in metal and nonmetal mines. However, numerous goafs are formed due to backward mining technology, low intensification degree, incomplete safety precautions, and the excessive exploitation of mineral resources, thus leading to severe environmental disruption. Accidents, like goaf collapse, are major geological disasters in mine production, and goaf stability evaluation is of great importance for reducing natural disasters in goafs and implementing environmental protection. The hazard types of environmental disruption caused by mine goafs were first analyzed in this study. Then, an influence factor index system of goaf stability was established, and a case study of a mine goaf in Henan Province was conducted using an analytic hierarchy process (AHP)-based fuzzy comprehensive evaluation model. Results show that the hazards of environmental disruption in mine goafs are manifested in the structural failure of surrounding buildings, massive water and soil loss, the exhaustion of water resources, the degradation of soil quality, and the remarkable reduction of overlying animals and plants. Technical factors exert the maximum influence on underground goaf stability with the total weight value reaching $72.42 \%$, and the influence weight of goaf span on goaf stability reaches $21.43 \%$, followed by goaf area and pillar distribution with influence weights of $18.58 \%$ and $11.17 \%$, respectively. Through fuzzy AHP-based comprehensive evaluation and calculation, the goaf stability of the Henan Sandaozhuang open-pit mine in the case study belongs to grade (ordinary), that is, the goaf stability is in the ordinary state, and the evaluation result reflects the reality. The study results have improved the reasonable stability and safety management scheme for complex multi-layer goaf and solved complex goaf hazards faced by Gaofeng mining area, so they will be of general significance for the environmental governance of other underground mine goafs.
\end{abstract}

\section{INTRODUCTION}

With the sustainable and rapid development of the national economy of China, the demand for and utilization of various mineral resources are continuously increasing. Meanwhile, Fig. 1 shows that the exploitation of mineral resources is increasing in quantity annually in China, though large reserves exist. Metal and nonmetal mines have many points and broad faces, but many underground goafs are formed due to backward mining technology, low intensification degree, incomplete safety precautions, and the excessive exploitation of mineral resources. In view of the complex underground goaf distribution and the difficulty in predicting goaf roof caving (collapse), the stability analysis of underground goafs has become a major limiting factor of the development of mines, and accidents, like goaf collapse, have become major geological disasters in mine production. Goafs are cavity areas left after underground mineral products are excavated. Natural rock masses are originally in a natural balanced state. All kinds of spaces, like roadways and stopes, must be excavated from rock masses to exploit mineral deposits, disrupting the natural balance state of rock masses. Furthermore, the exploited space changes the original stress field of the rock mass and thus generates a secondary stress field. Under the action of the secondary stress field, the rock mass around the exploited space undergoes deformation and even failure and movement until a new balance is reached. A mining area can be divided into old, present, and future mining areas according to the mining time.

However, as the open-stope method is adopted in most small- and medium-sized mines in China, the scale of the goaf left is extremely large. Meanwhile, some goafs have already become major risks to the safe production of mine enterprises due to the poor hydrogeological conditions in goafs and the harsh geological environmental conditions around them. Mining activities lead to surface subsidence, slope instability, ground fracture, and other geological 
disasters. The development of mineral resources will result in soil resource loss, the pollutant discharge in the development process of mineral resources will cause environmental pollution, and the whole mining activity will lead to the imbalance of the underground water system and aggravate the water and soil loss and land desertification in the mining area. These problems exist in the coal mining process and have a huge environmental impact on the entire mining area in the form of geological disasters, like goaf collapse, and a severe effect on the economic development, people's lives, and property safety in the mining area. With the exhaustion of mineral resources, most mine enterprises are in the residual ore recovery phase, and some are guilty of excessive exploitation so that the exposure areas of goafs are further enlarged. Moreover, the surrounding rock stability in goafs is degraded and the recovery safety is threatened under the impacts of water flow erosion and blast vibration.

\section{PAST STUDIES}

Environmental pollution and governance problems in mine goafs have always been among the main difficulties of mine enterprises. Domestic and foreign experts and scholars have carried out many theoretical research works and scientific practices. The main foreign mining countries have turned their attention to the goaf stability problem very early. Regarding the environmental disruption caused by goafs, Ma et al. (2012) deemed that the large-area continuous solid shallow-buried goaf group generated by the open-stope method would collapse completely because the partial instability of upright and roof led to the collapse of the whole mine, displaying the domino effect, that is, causing severe environmental disruption. Youhong et al. (2015) investigated the collapse mechanism of the third mining area in Gongchangling District, Liaoyang City and related influence factors and distribution laws through a geological survey.
Their results show that mining is the primary factor of surface subsidence, while underground water infiltration accelerates this process. Huang et al. (2017) deemed that the exploitation of China's coal resources would cause permanent fracture and the movement of the stratigraphic texture and thus cause the fracture and collapse of the overlying strata; furthermore, surface subsidence and water leakage at aquifers around the coal seam would occur. These phenomena would not only result in loss of land and water resources but would also lead to serious threats to and accidents in underground mining and further cause the destruction and degradation of the ecosystem. Zhao et al. (2018) introduced the coal stone backfill and banding mining method to perform case analysis of the Tangshan coal mine in Hebei Province, China, and their study suggests that the surface subsidence and coal stone caused by mining activity might seriously impact the nearby environment. Hengjie et al. (2018) believed that the coal mining processes in the whole world have left many goafs. If pillars fail to maintain permanent stability, sudden large-area goaf collapse might occur, which would cause serious environmental pollution. Ma et al. (2019) believe that the coal stones generated during the coal mining and dressing process are a severe threat to the ground environment and proposed a new governance method. The main researches on goaf stability are as follows. Whittles et al. (2006) developed an analysis method for predicting the possible influence of the shear strain generated in rock mass on the subsequent shaft stability and then provided a derivation method. Gao et al. (2016) deemed that underground coal mining would have a major adverse effect on road stability and proposed a numerical method combing SRM-UDEC (Synthetic Rock Mass-Universal Distinct Element Code) Trigon to investigate the roadway failure mechanism along unstable goafs. Chuanqu et al. (2006) thought that goaf stability is comprehensively influenced by multiple factors, such as the strength of surrounding rock, coal strength, mining depth, gaps in sur-

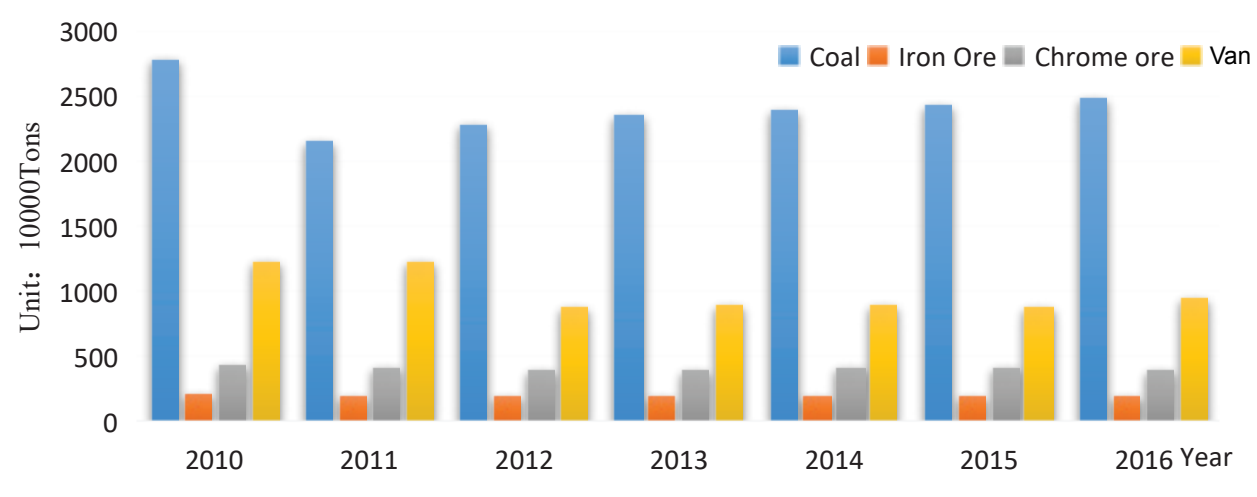

Fig. 1: Reserves of main mineral resource types in China during 2010-2016. 
rounding rock, mining operation, top coal thickness, and coal seam width, and thus constructed a subordinate function for the influence factors of gob-side roadway stability on a fully mechanized working face and built a grey fuzzy classification model to carry out an empirical study. Chen et al. (2010) included the microcosmic goaf governance problem into the innovative design of the mining method and probed the synergistic effect between the two problems. The catalyzed fission mining area of the 105\# ore body in Gaofeng Mining Area, Guangxi was taken as an example. Some typical goafs were selected, and their stability was calculated through the discrete element method according to their differences in scale, environmental conditions, and geo-stress field. The research results indicate that collaborative research on goafs in fission ore segments and goaf management can improve the safety of ore deposits. Li et al. (2016) evaluated the long-term stability of the rock strata above an old goaf and its possible influence on the buildings above the rock strata, analyzed the releasable space in the rock strata, proposed a stability evaluation method for the building foundation above the goaf under the abovementioned circumstance, and applied the proposed method to engineering practice. Feng (2018) explored the influences of the strength of backfill materials on the deformation of coal and the rock strata constituted by multiple goafs during the excavation process through the backfill method. The numerical results show that the supporting ability of the backfill materials in the goaf was enhanced with the increase of BMS (the strength of backfilling materials). Wu et al. (2018) believed that the mining process is accompanied by the gradual accumulation of disasters and selected 10 influence factors to evaluate the ground stability of goafs. According to level of each evaluation factor, the surveyed area was divided into four regions-the unstable, basic unstable, basic stable, and stable regions-based on the fuzzy comprehensive evaluation, and the study results would contribute to predicting and controlling the surface subsidence disaster caused by underground mining in similar areas. Yang et al. (2019) investigated the gob-side roadway stability under the disturbance of the underground coal face and raised concrete control measures. The existing literature indicates that studying the overall mine stability during the underground exploitation process helps mines take necessary measures to eliminate or reduce their potential safety hazards, like surface subsidence or collapse, effectively control ground pressure disasters, protect the surface environment, and realize green mining. On this basis, the hazard types of environmental disruption caused by mine goafs were analyzed first in this study. A mine in Henan Province was taken as an example, an influencing factor index system of goaf stability was established, and an analytic hierarchy process (AHP)-based fuzzy comprehensive evaluation method was used to evaluate the goaf stability of this mine. Qualitative and quantitative safety evaluations of the underground goaf stability were conducted, and goaf management measures were proposed according to the evaluation results for the mine to eliminate and control some unstable goafs. This will not only contribute to safe underground mining but also bring economic benefits to the mine.

\section{HAZARDS OF ENVIRONMENTAL DISRUPTION IN MINE GOAF}

\section{Structural Failure of Buildings}

Geological disasters related to goaf ground fracture present slow development. Geological disasters gradually emerge and escalate with the increasing number and scale of ground fracture activities. For instance, high tensile stress is generated inside buildings on ground fracture due to ground fracture activity. As the ground fracture activity continues to increase, cracks will generate after the tensile stress generated by buildings reaches the limit value and continuously propagate with the ground fracture activity, thus leading to the structural failure of buildings and finally influencing their overall stability. This process is generally a long-term process and not a sudden disaster.

\section{Massive Water and Soil Loss}

Under a shallow surface water table, a swamp area or water collection pool will form on the earth's surface when the underground water level at a sedimented low-lying place is approximate to or higher than the surface level, leading to certain water and soil loss. For land resources in goafs, the ground fracture will dewater the shallow groundwater and cause large-area damage to land and water resources. With the continuous coal mining activities, the surface water is influenced by "three zones," the surface runoffs leak and runoff along the fissure zone and then gradually decrease, the motion state of the underground water body is transformed from the original transverse motion into longitudinal motion, which reduces the surface water capacity and the underground water level by a large margin, and then a series of problems, such as the flow cutoff of surface spring water, emerges. When goafs are under the joint action of ground fracture, land erosion can be divided into rill, gully, and gravitational erosions. Rill erosion enlarges soil gaps with reduced capillary water content and increased gravitational water along with the formation of fine soil particles and the reduction of water content. Gully erosion cuts the land and causes land slope. Gravitational erosion leads to direct soil displacement under the action of gravity and water and can easily cause the direct occurrence of geological disasters, like collapse and landslide. 


\section{Exhaustion of Water Resources}

Continuous coal mining activities also influence the underground water circulating supply system and change the hydraulic connection between underground aquifers. Within the scope of a coal mining area, pit water infiltrates underground via the diversion fissure zone and replenishes the underground water, polluting the underground water, and the utilizable quantity of nearby underground water resources is reduced or even exhausted. Coal mining activities lead to underground water pollution. Given the existence of cracks at the upper strata in a goaf, the water recharge acquired by the lower aquifer in the vertical direction and the water content at the underlying aquifer increase. The degree of mineralization and hardness of underground water gradually increases during the long-term oxidation-reduction process, and the pollution also escalates every year.

\section{Degradation of Soil Quality}

The change in soil quality in the overlying region caused by mining-out is mainly reflected in the change in soil moisture content, $\mathrm{pH}$, rapidly available phosphorus, rapidly available potassium, and so on. Soil moisture content, porosity, and the contents of rapidly available phosphorus and potassium in the overlying region decrease due to mining-out. The comparative changes in moisture content and porosity directly indicate that ground fracture changes the soil water containing, holding and retaining capacities, and the soil $\mathrm{pH}$ value has a bearing on the effectiveness of soil nutrients. The comparative changes in the rapidly available phosphorus and potassium contents directly reflect the effect of ground fracture on soil fertility.

\section{Marked Reduction of Overlying Animals and Plants}

Given the influences of water and soil loss caused by the ground fracture in the goaf on water and soil environments, the growth of the overlying vegetations is degraded. Influenced by ground fracture, the damaged caused by the ground fracture to plant root systems influences the moisture and nutrient absorption of plant root systems and inhibits plant growth. Coal mining reduces the number of wild plant species, and the richness of wild species in the goaf is evidently lower than that in non-mined out area.

\section{GOAF STABILITY EVALUATION}

\section{Profile of AHP-Based Fuzzy Comprehensive Evaluation Model}

As a general rule, many factors should be considered in measuring and calculating complicated problems, like goaf stability, and these factors are located at different levels. Thus, the evaluation factors must be divided into several types according to one property. First, each type is comprehensively evaluated, and then high-level comprehensive evaluation is performed between different types based on the evaluation results of each type. In this way, the multilevel fuzzy comprehensive evaluation problem is generated. The multilevel fuzzy comprehensive evaluation model can be established through the following steps.

The evaluation factor set $(U)$ is divided into $m$ subsets according to one property, satisfying Formula (1):

$$
\left\{\begin{array}{l}
\sum_{i=1}^{m} U_{i}=U \\
U_{i} \cap U_{j}=\Phi(\mathbf{i} \neq \mathbf{j})
\end{array}\right\}
$$

Then, the second-level evaluation factor set is obtained using Formula (2):

$$
U=\left\{u_{1}, u_{2}, \ldots, u_{m}\right\}
$$

In Formula (2), $U_{i}=\left\{U_{i k}\right\}(i=1,2, \ldots, n)$, and the evaluation factors in each subset $\left(U_{i}\right)$ are evaluated through a single-level fuzzy comprehensive evaluation model. If the weight allocation of the factors in $U_{i}$ is $A_{i}$, then the evaluation decision matrix is $R_{i}$. Then, the comprehensive evaluation result of the $i^{\text {th }}$ subset $\left(U_{i}\right)$ is obtained as follows:

$$
B_{i}=A_{i} \times B_{i}=\left[b i_{1}, b_{i 2}, \ldots b_{i n}\right]
$$

$m$ evaluation factor subsets (i.e., $U_{i}(i=1,2, \ldots, m)$ in $U_{i}$ are comprehensively evaluated, and the evaluation decision matrix is:

$$
R=\left[\begin{array}{c}
B_{1} \\
B_{2} \\
\vdots \\
B_{m}
\end{array}\right]=\left[\begin{array}{cccc}
b_{11} & b_{12} & \cdots & b_{1 n} \\
b_{21} & b_{22} & \cdots & b_{2 n} \\
\vdots & \vdots & \ddots & \vdots \\
b_{m 1} & b_{m 2} & \cdots & b_{m n}
\end{array}\right]
$$

If the weight allocation of the factor subsets in $U$ is $A$, then the comprehensive evaluation result can be obtained as follows:

$$
B^{*}=A \times R
$$

$B^{*}$ in Formula (5) is not only the comprehensive evaluation result of $U$ but also that of all the evaluation factors in $U$.

\section{Index System and Study Object}

According to the existing research results of scholars, the important influence factors of goaf stability mainly depend on the three following aspects: the factors of the goaf itself, geological factors, and mining disturbance. The mutually independent influence factors for goaf stability, which consist of three first-level indexes and 14 second-level indexes, are finally formed as given in Table 1. 
Table 1: Influence Factors of Goaf Stability.

\begin{tabular}{|c|c|}
\hline First-level index & Second-level index \\
\hline \multirow{6}{*}{ Technical factors } & Area \\
\hline & Span \\
\hline & Pillar distribution \\
\hline & Burial depth of goaf \\
\hline & Thickness of overlying strata \\
\hline & Span-depth ratio of goaf \\
\hline \multirow{5}{*}{ Geological factors } & Rock mass structure \\
\hline & Geological structure \\
\hline & Rock mass quality \\
\hline & Geographic orientation \\
\hline & Underground water activity \\
\hline \multirow{3}{*}{ Other factors } & Conditions of adjacent goaf \\
\hline & Mining disturbance \\
\hline & Protective measures \\
\hline
\end{tabular}

The study object is the Sandaozhuang mining area, which is located in Lengshui Town, Luanchuan County, Luoyang City, Henan Province and a subordinate of China Molybdenum Co., Ltd. The mining area is approximately 20 miles from Luanchuan County. The Sandaozhuang Lingyucheng Ridge in the mining area is a watershed for two major water systems, the Yangtze and Yellow rivers. The northern water system flows into the Yellow River through the Yihe River, while the southern water system flows into the Yangtze River via the Xiaohe River and the Laoguan River. This mining area has a high-mountain climate that is cool in summer and severe cold in winter. Located in the Funiu Mountain area, this mining area has a large population with a relatively small land and focuses on agriculture with auxiliary industry, forestry, and mining industry. The present production capacity of the Sandaozhuang open-pit mine is 30,000 t/day. The mine started as small-scale underground mining in the 1960s, employing the open-stope method. Owing to excessive and unplanned excavations and mining in the entire mining area, severe destruction and waste of national resources have been experienced. Meanwhile, many irregular goafs are formed in the mining area.

\section{EMPIRICAL STUDY}

\section{Weight Determination}

The AHP was used in this study to determine the weights of influence factors. The AHP judgment matrix is given in Tables 2-5.

The final calculated weight results are provided in Table 6.

According to Table 6, technical factors have the most influence on underground goaf stability, with their total weight value reaching $72.42 \%$, while the total weight of the other factors is the minimum, that is, $8.25 \%$. Therefore, importance should be attached to subfactors in technical factors in the goaf stability analysis. Among the subfactors, the influence weight of goaf span on goaf stability reaches $21.43 \%$, and thus the most important influence factor, followed by goaf area and pillar distribution, with respective influence weights of $18.58 \%$ and $11.17 \%$, respectively. Hence, these main influence factors should be highlighted in the goaf stability evaluation and calculation process.

Table 2: Judgment matrix of First-level factors.

\begin{tabular}{|llll|}
\hline & Technical factor & Geological factor & Other factors \\
\hline Technical factor & 1.00 & 5.00 & 7.00 \\
Geological factor & 0.20 & 1.00 & 3.00 \\
Other factors & 0.14 & 0.33 & 1.00 \\
\hline
\end{tabular}


Table 3: Judgment matrix of technical factors.

\begin{tabular}{|lllllll|} 
& Area & Span & $\begin{array}{l}\text { Pillar } \\
\text { distribution }\end{array}$ & Burial depth of goaf & $\begin{array}{l}\text { Thickness of overlying } \\
\text { strata }\end{array}$ & Span-depth ratio of goaf \\
\hline Area & 1.00 & 1.00 & 3.00 & 4.00 & 1.00 & 5.00 \\
Span & 1.00 & 1.00 & 2.00 & 4.00 & 3.00 & 3.00 \\
Pillar distribution & 0.33 & 0.50 & 1.00 & 5.00 & 0.33 & 0.50 \\
Burial depth of goaf & 0.25 & 0.25 & 0.20 & 1.00 & 1.00 & 0.33 \\
Thickness of overlying strata & 1.00 & 0.20 & 0.33 & 3.00 & 1.00 & 1.00 \\
Span-depth ratio of goaf & 0.33 & 0.33 & 2.00 & 3.00 & & 1.00 \\
\hline
\end{tabular}

Table 4: Judgment matrix of geological factors.

\begin{tabular}{|llllll|}
\hline & Rock mass structure & Geological structure & Rock mass quality & $\begin{array}{l}\text { Geographic } \\
\text { orientation }\end{array}$ & $\begin{array}{c}\text { Underground water } \\
\text { activity }\end{array}$ \\
\hline Rock mass structure & 1.00 & 3.00 & 0.20 & 0.33 & 7.00 \\
Geological structure & 0.33 & 1.00 & 3.00 & 1.00 & 5.00 \\
Rock mass quality & 5.00 & 0.33 & 1.00 & 3.33 & 1.00 \\
Geographic orientation & 3.00 & 1.00 & 0.00 & 0.20 & 5.00 \\
Underground water activity & 0.14 & 0.20 & & 0.33 & 1.00 \\
\hline
\end{tabular}

Table 5: Judgment matrix of other factors.

\begin{tabular}{|llll|}
\hline & Conditions of adjacent goaf & Mining disturbance & Protective measures \\
\hline Conditions of adjacent goaf & 1.00 & 3.00 & 7.00 \\
Mining disturbance & 0.33 & 1.00 & 3.00 \\
Protective measures & 0.14 & 0.33 & 1.00 \\
\hline
\end{tabular}

Table 6: Index weights determined via AHP.

\begin{tabular}{|c|c|c|c|c|}
\hline First-level index & First-level weight & Second-level index & Second-level index weight & Combined weight \\
\hline \multirow{6}{*}{ Technical factor } & \multirow{6}{*}{0.7242} & Goaf area & 0.2566 & 0.1858 \\
\hline & & Goaf span & 0.2959 & 0.2143 \\
\hline & & Pillar distribution & 0.1542 & 0.1117 \\
\hline & & Burial depth of goaf & 0.0468 & 0.0339 \\
\hline & & Thickness of overlying strata & 0.1178 & 0.0853 \\
\hline & & Span-depth ratio of goaf & 0.1286 & 0.0931 \\
\hline \multirow{5}{*}{ Geological factor } & \multirow{5}{*}{0.1933} & Rock mass structure & 0.2246 & 0.0434 \\
\hline & & Geological structure & 0.2403 & 0.0464 \\
\hline & & Rock mass quality & 0.1960 & 0.0379 \\
\hline & & Geographic orientation & 0.2966 & 0.0573 \\
\hline & & Underground water activity & 0.0426 & 0.0082 \\
\hline \multirow{3}{*}{ Other factors } & \multirow{3}{*}{0.0825} & Conditions of adjacent goaf & 0.6698 & 0.0553 \\
\hline & & Mining disturbance & 0.2427 & 0.0200 \\
\hline & & Protective measures & 0.0875 & 0.0072 \\
\hline
\end{tabular}


Table 7: Membership evaluation grade sets of second-level indexes.

\begin{tabular}{|c|c|c|c|c|c|}
\hline \multirow{2}{*}{ Second-level index } & \multicolumn{5}{|c|}{ Evaluation grade } \\
\hline & Very good & Relatively good & Ordinary & Relatively poor & Poor \\
\hline Goaf area & 0.2 & 0.3 & 0.3 & 0.2 & 0 \\
\hline Goaf span & 0.3 & 0.1 & 0.5 & 0.1 & 0 \\
\hline Pillar distribution & 0.2 & 0.2 & 0.1 & 0.4 & 0.1 \\
\hline Burial depth of goaf & 0.3 & 0.2 & 0.2 & 0.1 & 0.2 \\
\hline Thickness of overlying strata & 0.1 & 0.2 & 0.2 & 0.3 & 0.2 \\
\hline Span-depth ratio of goaf & 0.4 & 0.1 & 0 & 0.3 & 0.2 \\
\hline Rock mass structure & 0.3 & 0.1 & 0.3 & 0.3 & 0 \\
\hline Geological structure & 0.2 & 0.4 & 0.1 & 0.1 & 0.2 \\
\hline Rock mass quality & 0.3 & 0.2 & 0.2 & 0.1 & 0.2 \\
\hline Geographic orientation & 0.4 & 0 & 0.1 & 0.2 & 0.3 \\
\hline Underground water activity & 0.1 & 0.4 & 0.1 & 0 & 0.4 \\
\hline Conditions of adjacent goaf & 0.3 & 0.2 & 0.1 & 0.3 & 0.1 \\
\hline Mining disturbance & 0.5 & 0 & 0 & 0.3 & 0.2 \\
\hline Protective measures & 0.4 & 0.3 & 0.2 & 0.1 & 0 \\
\hline
\end{tabular}

\section{Membership Analysis}

A total of 18 mine safety experts were invited to evaluate the quantitative indexes, the evaluation grade set of each second-level index was obtained, and their memberships were obtained through fuzzy statistics as shown in Table 7.

\section{Fuzzy Synthetic Calculation}

According to Formulas (2)-(5), a fuzzy calculation of the second-level indexes is carried out one by one to obtain the following matrix.

$$
B_{i}=\left[\begin{array}{lllll}
0.2342 & 0.1832 & 0.3108 & 0.1839 & 0.0879 \\
0.2379 & 0.3043 & 0.1240 & 0.1875 & 0.1465 \\
0.1816 & 0.1485 & 0.2670 & 0.2515 & 0.1515
\end{array}\right]
$$

According to Formula (5), the following is finally obtained:

$$
\begin{aligned}
& B^{*}=A \times R=\left[\begin{array}{c}
0.7242 \\
0.1933 \\
0.0825
\end{array}\right]^{T} *\left[\begin{array}{lllll}
0.2342 & 0.1832 & 0.3108 & 0.1839 & 0.0879 \\
0.2379 & 0.3043 & 0.1240 & 0.1875 & 0.1465 \\
0.1816 & 0.1485 & 0.2670 & 0.2515 & 0.1515
\end{array}\right] \\
& =\left[\begin{array}{lllll}
0.2305 & 0.2037 & 0.2711 & 0.1901 & 0.1045
\end{array}\right]
\end{aligned}
$$

According to the actual situation in the goaf site and considering the maximum membership principle, the goaf stability belongs to grade (ordinary) through the fuzzy AHP, that is, the goaf stability is in an ordinary state, and the evaluation result is consistent with the reality. The study results indicate that most goafs within the Sandaozhuang open-pit mine are of unstable and extremely unstable goaf grades, and large-scale goaf disaster can easily occur any time.

\section{CONCLUSION}

Low goaf stability is one of the geological disasters that trigger mine accidents and can lead to surface subsidence, surface cracks, wall caving, earthquake, and so on, resulting in immeasurable losses to the production of mine enterprises and endangering employees. To prevent and reduce the severe hazards brought by goafs and guarantee safe and normal mine production, a comprehensive evaluation study of goaf stability must be conducted. First, an influence factor index system of goaf stability was built, and an AHP-based fuzzy comprehensive evaluation model was used in a case study of a mine goaf in Henan Province. The study results indicate that the mine goaf will result in the structural failure of surrounding buildings, massive water and soil loss, the exhaustion of water resources, the degradation of soil quality, and an evident reduction of overlying animals and plants. Technical factors have the maximum influence on underground goaf stability, with the total weight value reaching $72.42 \%$, while those of the goaf span, the goaf area, and the pillar distribution are $21.43 \%, 18.58 \%$, and $11.17 \%$, respectively. The stability of the Sandaozhuang open-pit mine goaf in Henan Province belongs to grade (ordinary), that is, the goaf stability is under ordinary state, and the evaluation result is consistent with the reality. Thus, in-depth research regarding 
enriching the factor system of goaf stability is suggested to establish a more accurate and complicated evaluation model and acquire related mechanical parameters needed for the reliability analysis of goaf stability, such as the compressive strength, tensile stress, elasticity modulus, and density of the ore-bearing rocks in the goaf.

\section{ACKNOWLEDGEMENTS}

This work was supported by the National Natural Science Foundation of China (51474045); Key Scientific Research Projects of Colleges and Universities in Henan Province (18A560019, 19A560023, 20B560013).

\section{REFERENCES}

Chen, Q.F., Zhou, K.P., Hu, J.H. and Zhang, S.C. 2010. Synergism study of mining and goaf treatment in cataclastic ore section. Zhongnan Daxue Xuebao (Ziran Kexue Ban)/Journal of Central South University (Science and Technology), 41(2): 728-735.

Gao Fu qiang, Stead Doug, Kang Hong Pu and Wu Yong Zheng, 2014. Discrete element modelling of deformation and damage of a roadway driven along an unstable goaf - A case study. International Journal of Coal Geology,127: 100-110.

Huang Jiu, Tian Chuyuan, Xing Longfei, Bian Zhengfu and Miao Xiexing 2017. Green and sustainable mining: Underground coal mine fully mechanized solid dense stowing-mining method. Sustainability, 9(8): 1-18.

Luan, Hengjie, Lin Huili, Jiang Yu jing and Wang Yahua, 2018. Risks induced by room mining goaf and their assessment: A case study in the Shenfu-Dongsheng mining area. Sustainability, 10(3): 631.
Li, Liang, Wu, K. and Zhou, D.W. 2016. Evaluation theory and application of foundation stability of new buildings over an old goaf using longwall mining technology. Environmental Earth Sciences, 75(9): 763.

Ma, Dan, Liu Hong, Li Jiang, Zhou Xi and Long Zi 2019. The role of gangue on the mitigation of mining-induced hazards and environmental pollution: An experimental investigation. Science of the Total Environment, 10: 436-448.

Ma, Haitao, Wang, J. and Wang, Y. 2012. Study on mechanics and domino effect of large-scale goaf cave-in. Safety Science, 50(4): 689-694.

Whittles, D.N., Lowndes, L.S., Kingman, S.W., Yates, C. and Jobling, S. 2006. Geomechanical factors affecting the installation and stability of a surface goaf well at a deep UK coal mine. Archives of Mining Sciences, 51(2): 197-230.

Wu, Zhiyong, Niu Qinghe, Li Wenping, Lin Naing Htun and Liu Shiliang 2018. Ground stability evaluation of a coal-mining area: a case study of Yingshouyingzi mining area, China. Journal of Geophysics and Engineering, 15(5): 2252-2265.

Xiaojun Feng and Qiming Zhang, 2018. The effect of backfilling materials on the deformation of coal and rock strata containing multiple Goaf: A Numerical Study. Minerals, 8(6): 224.

Yang, Houqiang, Han Changliang, Nong Zhang, Sun Changlun, Pan Dongjiang and Dong Minghui, 2019. Stability control of a goaf-side roadway under the mining disturbance of an adjacent coal working face in an underground mine. Sustainability, 11(22): 6398.

Youhong, Xiangding and Wenfei, Lina, 2015. Mechanism and stability evaluation of goaf ground subsidence in the third mining area in Gong Changling District, China. Arabian Journal of Geosciences, 8: 639-646.

Zhu, Chuanqu, Weijun, W. and Shiliang, S. 2006. Classification model and its application of stability of roadway driving along next goaf for fully-mechanized caving face. Engineering Science, 8(3): 35-38.

Zhao, Tongbin, Shuqi Ma and Zhenyu Zhang 2018. Ground control monitoring in backfilled strip mining under the metropolitan district: Case Study. International Journal of Geomechanics, 18(7): 05018003. 